\title{
Produtividade de pastagens degradadas de Brachiaria brizantha cv. Marandu sobressemeadas com Desmodium ovalifolium CIAT-350
}

\author{
Newton de Lucena Costa ${ }^{1}$, Claudio Ramalho Townsend ${ }^{2}$, João Avelar Magalhães ${ }^{3}$, Valdinei \\ Tadeu Paulino ${ }^{4}$, Antônio Neri Azevedo Rodrigues ${ }^{5}$ \\ ${ }^{1}$ Eng. Agr., D.Sc., Embrapa Roraima. Boa Vista, Roraima. \\ ${ }^{2}$ Zootecnista, D.Sc., Embrapa Clima Temperado. Pelotas, Rio Grande do Sul. \\ ${ }^{3}$ Médico Veterinário, D.Sc., Embrapa Meio-Norte. Parnaíba, Piauí. \\ ${ }^{4}$ Eng. Agr., Ph.D., Instituto de Zootecnia. Nova Odessa, São Paulo. \\ ${ }^{5}$ Eng. Agr., M.Sc., Instituto Federal de Rondônia, Colorado do Oeste, Rondônia. Doutorando UFPR, \\ Curitiba, Paraná. \\ *Autor para correspondência, E-mail: newtonlucena@yahoo.com.br
}

\begin{abstract}
RESUMO. Avaliaram-se os efeitos de métodos de sobressemeadura (roçagem, aração, gradagem, aração + gradagem e plantio manual) de Desmodium ovalifolium CIAT-350 e da adubação fosfatada ( 0 e $50 \mathrm{~kg}$ de $\mathrm{P}_{2} \mathrm{O}_{5} / \mathrm{ha}$ ) na recuperação de pastagens degradadas de Brachiaria brizantha cv. Marandu. A sobressemeadura da leguminosa, independentemente da adubação fosfatada, mostrou-se uma prática tecnicamente viável para a recuperação de pastagens da gramínea. Os rendimentos de matéria seca da gramínea e da leguminosa foram $(\mathrm{P}<0,05)$ incrementados pela adubação fosfatada, ocorrendo o inverso em relação às plantas invasoras. Considerando-se a disponibilidade total de forragem e a composição botânica da pastagem (razão gramínea:leguminosa satisfatória e que assegure a estabilidade produtiva da consorciação), a sobressemeadura pelo plantio manual com matraca ou após a roçagem, associadas à aplicação de fósforo, foram os métodos mais eficientes para a introdução da leguminosa em pastagens degradadas de $B$. brizantha $\mathrm{cv}$. Marandu.
\end{abstract}

Palavras chave: Aração, gradagem, matéria seca, plantas invasoras, roçagem

\section{Forage yield of degraded pastures of Brachiaria brizantha cv. Marandu over sowing with Desmodium ovalifolium CIAT-350}

\begin{abstract}
The effects of over sowing methods of Desmodium ovalifolium CIAT350 (mowing, plowing, harrowing, plowing + harrowing and manual seeding) and phosphate $(\mathrm{P})$ fertilization ( 0 and $50 \mathrm{~kg}$ of $\mathrm{P}_{2} \mathrm{O}_{5} / \mathrm{ha}$ ), on reclamation of Brachiaria brizantha cv. Marandu degraded pastures were evaluated. Legume introduction, irrespective of $\mathrm{P}$ fertilization, showed an effective agronomic technique for pasture reclamation. Grass and legume dry matter (DM) yields were improved by $\mathrm{P}$ application, while DM of weeds were depressed. In order to obtain greater forage yields and better ratio grass:legumes that ensure the productive stability of the mixture, the manual seeding and mowing plus $\mathrm{P}$ application were the most effective methods for oversowing the legume on grass degraded pastures.
\end{abstract}

Keywords: Dry matter, harrowing, mowing, plowing, weeds

\section{Introdução}

Na Amazônia Ocidental, cerca de dez milhões de hectares, originalmente sob cobertura de florestas, estão, atualmente, ocupados com pastagens cultivadas. Desta área, cerca de $40 \%$ apresenta pastagens em diferentes estágios de degradação, o que reflete na necessidade de novos desmatamentos, a fim de alimentar adequadamente os rebanhos, resultando numa pecuária itinerante. 
O processo de degradação se manifesta pelo declínio gradual da produtividade das plantas forrageiras, devido a vários fatores, tais como a baixa fertilidade natural dos solos, manejo inadequado das pastagens (altas cargas animal e pastejo contínuo), ausência de fertilizações, uso indiscriminado do fogo, compactação do solo e as altas pressões bióticas (pragas e doenças), o que culmina com a dominância total da área por plantas invasoras (Veiga \& Serrão, 1987; Silva \& Jacques, 1994; Costa, 1996; Costa et al., 1997). A baixa disponibilidade de nitrogênio, notadamente nos ecossistemas em que há predominância de gramíneas, tem sido apontada como a principal causa da degradação das pastagens (Moreira, 2006). Face aos altos custos dos fertilizantes nitrogenados, a introdução de leguminosas em pastagens degradadas, vem sendo recomendada como a alternativa mais eficiente e econômica para o fornecimento de nitrogênio ao sistema solo-planta, além de aumentar a capacidade de suporte e melhorar o valor nutritivo da forragem em oferta (Daza, 1990; Moreira \& Arruda, 1990; Moreira, 2006).

Dentre várias leguminosas forrageiras introduzidas e avaliadas em Rondônia, o gênero Desmodium destacou-se entre os mais promissores, pois, além de sua excelente produtividade de forragem, moderado valor nutritivo e grande agressividade, apresenta boa adaptação a solos de baixa fertilidade e alta tolerância à seca (Costa et al., 1995; Townsend et al., 2012). Os estudos conduzidos por Costa \& Oliveira (1999) também revelaram que dentre os genótipos testados, o $D$. ovalifolium CIAT-350 foi o mais produtivo (23,9 t de MS/ha/ano), com teores médios de $12 \%$ de proteína bruta.

Neste trabalho avaliaram-se os efeitos de métodos de sobressemeadura de Desmodium ovalifolium CIAT-350 e da adubação fosfatada na recuperação de pastagens degradadas de Brachiaria brizantha cv. Marandu.

\section{Material e Métodos}

O ensaio foi conduzido no Campo Experimental da Embrapa Rondônia, localizado no município de Porto Velho. O clima da região é tropical do tipo Am, com temperatura média de $24,5^{\circ} \mathrm{C}$, precipitação entre 2.000 e $2.500 \mathrm{~mm}$, com estação seca bem definida (junho a setembro) e umidade relativa do ar média anual em torno de $89 \%$.
O solo da área experimental é um Latossolo Amarelo, textura argilosa, fase floresta, com as seguintes características químicas: $\mathrm{pH}$ em água $(1: 2,5)=4,8 ; \mathrm{Al}=1,4 \mathrm{cmol}_{\mathrm{c}} / \mathrm{dm}^{3} ; \mathrm{Ca}+\mathrm{Mg}=2,2$ $\mathrm{cmol}_{\mathrm{c}} / \mathrm{dm}^{3} ; \mathrm{P}=1,0 \mathrm{mg} / \mathrm{kg} ; \mathrm{K}=0,04 \mathrm{cmol}_{\mathrm{d}} / \mathrm{dm}^{3} \mathrm{e}$ matéria orgânica $=3,02 \%$.

A área experimental consistiu de uma pastagem de Brachiaria brizantha cv. Marandu, estabelecida há oito anos e caracterizada como degradada devido ao baixo vigor da gramínea, baixa disponibilidade de forragem e predominância de plantas invasoras (30 a 50\%). $\mathrm{O}$ delineamento experimental foi em blocos casualizados com parcelas divididas e três repetições. Os métodos de sobressemeadura da leguminosa (roçagem, aração, gradagem, aração + gradagem e plantio manual com matraca) representavam as parcelas principais e, as doses de fósforo $\left(0\right.$ e $50 \mathrm{~kg}$ de $\left.\mathrm{P}_{2} \mathrm{O}_{5} / \mathrm{ha}\right)$, as subparcelas. A adubação de estabelecimento constou da aplicação de $60 \mathrm{~kg}$ de $\mathrm{k}_{2} \mathrm{O} / \mathrm{ha}$ (cloreto de potássio). O fósforo foi aplicado a lanço, sob a forma de superfosfato triplo. A leguminosa foi semeada a lanço, utilizando-se $1,5 \mathrm{~kg}$ de sementes/ha (Valor Cultural $=90 \%)$.

Os parâmetros avaliados foram disponibilidade de matéria seca (MS) da gramínea, leguminosas e das plantas invasoras. As avaliações foram realizadas a intervalos de 12 semanas, pelos cortes mecânicos efetuados a uma altura de $20 \mathrm{~cm}$ acima do solo.

\section{Resultados e Discussão}

A análise da variância revelou efeito $(\mathrm{P}<0,05)$ para o efeito de métodos de sobressemeadura e adubação fosfatada sobre a disponibilidade de forragem (Tabela 1). Para a componente gramínea, os maiores rendimentos de MS foram verificados nos tratamentos testemunha $(8,86$ t/ha) e matraca (6,47 t/ha), ambos na presença de adubação fosfatada. A aração + gradagem, independentemente da adubação fosfatada foi o tratamento que proporcionou os menores rendimentos de MS, como consequência da maior destruição de plantas da gramínea na pastagem, o que afetou negativamente sua recuperação e competitividade.

Os rendimentos de MS da leguminosa e das plantas invasoras foram diretamente proporcionais à intensidade de preparo do solo. Para a leguminosa, os maiores rendimentos foram obtidos com a aração (6,90 t/ha) e aração + gradagem $(5,60 \mathrm{t} / \mathrm{ha})$, respectivamente na 
presença e ausência de fertilização fosfatada, enquanto que para as plantas invasoras, a aração + gradagem $(3,42$ e 3,33 t/ha) independentemente da aplicação de fósforo resultou nas maiores produções de MS. Para a soma dos componentes (gramínea + leguminosa), a aração (12,70 t/ha), a gradagem $(10,93 \mathrm{t} / \mathrm{ha})$ e a roçagem $(10,12 \mathrm{t} / \mathrm{ha})$, associadas à adubação fosfatada, forneceram as maiores disponibilidades de MS, as quais superaram em 153, 118 e $102 \%$, respectivamente, as obtidas com o tratamento testemunha sem a aplicação de fósforo.

Tabela 1. Disponibilidade de matéria seca de pastagens degradadas de B. brizantha cv. Marandu, submetidas a diferentes métodos de sobressemeadura de D. ovalifolium CIAT-350, em função da adubação fosfatada.

\begin{tabular}{lccccc}
\hline $\begin{array}{l}\text { Métodos de } \\
\text { sobressemeadura }\end{array}$ & $\begin{array}{c}\text { Fósforo } \\
\left(\mathrm{kg} \mathrm{P}_{2} \mathrm{O}_{5} / \mathrm{ha}\right)\end{array}$ & $\begin{array}{c}\text { Gramínea } \\
(\mathrm{t} / \mathrm{ha})\end{array}$ & $\begin{array}{c}\text { Leguminosa } \\
(\mathrm{t} / \mathrm{ha})\end{array}$ & $\begin{array}{c}\text { Gram. }+ \text { Leg. } \\
(\mathrm{t} / \mathrm{ha})\end{array}$ & $\begin{array}{c}\text { Plantas } \\
\text { Invasoras } \\
(\mathrm{t} / \mathrm{ha})\end{array}$ \\
\hline Testemunha & 0 & $5,01 \mathrm{~cd}$ & - & $5,01 \mathrm{f}$ & $2,29 \mathrm{c}(31,4)^{*}$ \\
& 50 & $8,86 \mathrm{a}$ & - & $8,86 \mathrm{~cd}$ & $2,70 \mathrm{bc}(23,3)$ \\
Roçagem & 0 & $3,62 \mathrm{de}$ & $2,51 \mathrm{e}(32,8)^{*}$ & $6,13 \mathrm{ef}$ & $1,51 \mathrm{de}(19,7)$ \\
& 50 & $6,04 \mathrm{bc}$ & $4,08 \mathrm{~cd}(35,4)$ & $10,12 \mathrm{bc}$ & $1,39 \mathrm{e}(12,1)$ \\
Aração (A) & 0 & $3,65 \mathrm{de}$ & $3,78 \mathrm{~cd}(42,7)$ & $7,43 \mathrm{de}$ & $1,43 \mathrm{de}(16,1)$ \\
& 50 & $5,80 \mathrm{bc}$ & $6,90 \mathrm{a}(49,6)$ & $12,70 \mathrm{a}$ & $1,20 \mathrm{e}(8,7)$ \\
Gradagem (G) & 0 & $3,18 \mathrm{e}$ & $4,13 \mathrm{~cd}(44,3)$ & $7,31 \mathrm{de}$ & $2,01 \mathrm{~cd}(21,6)$ \\
& 50 & $6,06 \mathrm{bc}$ & $4,89 \mathrm{bc}(39,8)$ & $10,93 \mathrm{ab}$ & $1,35 \mathrm{e}(11,0)$ \\
A + G & 0 & $2,77 \mathrm{e}$ & $5,60 \mathrm{~b}(47,5)$ & $8,37 \mathrm{cde}$ & $3,42 \mathrm{a}(29,0)$ \\
& 50 & $3,56 \mathrm{de}$ & $4,03 \mathrm{~cd}(36,9)$ & $7,59 \mathrm{de}$ & $3,33 \mathrm{ab}(30,5)$ \\
Matraca & 0 & $4,82 \mathrm{~cd}$ & $2,19 \mathrm{e}(26,9)$ & $7,01 \mathrm{e}$ & $1,14 \mathrm{e}(14,0)$ \\
\hline
\end{tabular}

- Nas colunas, médias seguidas de mesma letra não diferem entre si ( $\mathrm{P}>0,05)$ pelo teste de Tukey.

*Percentual em relação à disponibilidade total de matéria seca.

No entanto, considerando-se os rendimentos totais de MS e as melhores razões gramínea:leguminosa, o plantio com matraca e a roçagem, ambas na presença de fertilização fosfatada, foram os métodos que proporcionaram um satisfatório estabelecimento da leguminosa. A sobressemeadura após a aração ou a gradagem, apesar de proporcionar rendimentos de MS semelhantes aos registrados com a matraca ou roçagem, implicou em elevados percentuais da leguminosa, o que pode comprometer a estabilidade da consorciação com o decorrer do tempo de utilização da pastagem. Da mesma forma, Costa (2004) constatou que a matraca e a roçagem, independentemente da fertilização fosfatada, foram os métodos mais eficientes para a introdução de Pueraria phaseoloides em pastagens degradadas de $B$. brizantha $\mathrm{cv}$. Marandu. No entanto, Moreira \& Arruda (1990) e Daza (1990) verificaram que a aração e a gradagem foram os métodos mais efetivos para a introdução de $P$. phaseoloides e Calopogonium mucunoides, respectivamente, em pastagens degradadas de Brachiaria decumbens. Em média, a adubação fosfatada proporcionou incrementos de 54,6 e 23,5\%, respectivamente, nos rendimentos de MS da gramínea e da leguminosa. Resultados semelhantes foram reportados por Gomide \& Obeid (1979) e Ferrufino (1990) para pastagens de Hyparrhenia rufa e $B$. decumbens, recuperadas com a introdução de leguminosas e adubação fosfatada.

No manejo de pastagens consorciadas buscase a estabilidade de sua composição botânica, notadamente quanto a participação e persistência da leguminosa, considerada como componente mais valioso e instável da consorciação (Andrade \& Ferreira, 1981; Townsend et al., 2012). Em regiões tropicais, a proporção adequada de leguminosas em pastagens consorciadas está na faixa de 20 a $45 \%$ da disponibilidade total de forragem, visando potencializar os benefícios decorrentes de sua presença, em termos de fixação biológica de nitrogênio e maior 
concentração de nutrientes da forragem em oferta (Thomas, 1992; Ribeiro et al., 2007). A persistência da leguminosa depende diretamente do sistema e da pressão de pastejo utilizada. Em geral, o pastejo contínuo e o alternado favorecem a permanência das leguminosas, notadamente as de baixa palatabilidade como o $D$. ovalifolium CIAT-350 e são recomendados como ferramentas de manejo para assegurar sua manutenção na pastagem, considerando-se as variações estacionais da oferta de forragem, notadamente durante o período seco (Townsend et al., 2012). Em alguns casos ajustes de manejo devem ser feitos para evitar que a leguminosa, em face de sua agressividade, domine a gramínea, principalmente quando são utilizadas altas pressões de pastejo em regiões sem período seco bem definido (Ribeiro et al., 2007).

\section{Conclusões}

A sobressemeadura da leguminosa, independentemente da adubação fosfatada, mostrou-se uma prática tecnicamente viável para a recuperação de pastagens de $B$. brizantha $\mathrm{cv}$. Marandu;

Os rendimentos de MS da gramínea e da leguminosa foram positivamente afetados pela adubação fosfatada, ocorrendo o inverso em relação às plantas invasoras;

Considerando-se a disponibilidade total de forragem e a composição botânica da pastagem, a sobressemeadura através do plantio manual com matraca ou após a roçagem, associada à aplicação de fósforo, foram os métodos mais eficientes para a introdução da leguminosa em pastagens degradadas de $B$. brizantha $\mathrm{cv}$. Marandu.

\section{Referências Bibliográficas}

Andrade, I. F. \& Ferreira, J. G. 1981. Introdução de leguminosas tropicais em pastagem estabelecida de capim-jaraguá. Revista Brasileira de Zootecnia, 10, 427-449.

Costa, N. L. 1996. Adubação fosfatada na recuperação de pastagens degradadas da região amazônica. Lavoura Arrozeira, 49, 1619.

Costa, N. L. 2004. Formação, manejo e recuperação de pastagens em Rondônia. Porto Velho: Embrapa Rondônia, 217p.

Costa, N. L. \& Oliveira, J. R. C. 1999. Rendimento de matéria seca e composição química de genótipos de Desmodium em
Rondônia. Pesquisa Agropecuária Gaúcha, 5, 77-81.

Costa, N. L., Oliveira, J. R. C. \& Magalhães, J.A. 1995. Produção e composição química de leguminosas forrageiras em Rondônia. Lavoura Arrozeira, 48, 422-424.

Costa, N. L., Townsend, C. R., Magalhães, J. A. \& Pereira, R. G. A. 1997. Leguminosas forrageiras na recuperação de pastagens degradadas da região amazônica.Porto Velho: EMBRAPA-CPAF Rondônia, 21p. (Documentos, 36).

Daza, L. A. 1990. Recuperación de Brachiaria decumbens tapf. Mediante prácticas agronómicas. In: Reunión de la Red Internacional de Evaluación de Pastos Tropicales, 1., Lima, Peru. Memórias... Cali, Colombia: CIAT, 2, 929-934.

Ferrufino, A. 1990. Establecimiento de leguminosas forrajeras en praderas poco productivas de Brachiaria decumbens. In: Reunión de la Red Internacional de Evaluación de Pastos Tropicales, 1., 1990, Lima, Peru. Memórias... Cali, Colombia: CIAT, 2, p.993-998.

Gomide, J. A. \& Obeid, J. A. 1979. Introdução de leguminosas tropicais em pastagens de gramíneas. Revista da Sociedade Brasileira de Zootecnia, 8, 563-609.

Moreira, A. L. 2006. Melhoramento de pastagens através da técnica da sobressemeadura de forrageiras de inverno. Pesquisa \& Tecnologia, 3, 1-9.

Moreira, E. M. \& Arruda, N. G. 1990. Métodos de introdução de Pueraria phaseoloides em pastagens de Brachiaria decumbens. In: Reunión de aa Red Internacional de Evaluación de Pastos Tropicales, 1., 1990, Lima, Peru. Memórias... Cali, Colômbia: CIAT, 2, 945-948.

Ribeiro, R. C., Rossiello, R. P., Macedo, R. O. \& Barbieri, E. 2007. Introdução de desmódio em pastagem estabelecida de Brachiaria humidicola: densidade e frequência da leguminosa no consórcio. Revista da Universidade Rural, 27, 41-49.

Silva, J. L. S. \& Jacques, A. V. A. 1994. Disponibilidade de forragem de uma pastagem natural sobressemeada com leguminosas perenes de estação quente. Revista Brasileira de Zootecnia, 22, 920-928 
Thomas, R. J. 1992. The role of the legume in the nitrogen cycle of productive and sustainable pastures. Grass and Forage Science, 47, 133142.

Townsend, C. R.; Costa, N. L.; Mendes, A. M, Pereira, R. G. A.; Nascimento, L. E. S. \& Magalhães, J. A. 2012. Compactação de um Latossolo Amarelo sob pastagem submetida a diferentes métodos de introdução de leguminosas forrageiras. Pubvet, 6, Art. 1339

Veiga, J. B. \& Serrão, E. A. S. 1987. Recuperación de pasturas en la región este de la Amazonía brasileña. Pasturas Tropicales, 9, 40-43.

Recebido em Dezembro 10, 2014

Aceito em Maio 27, 2015

License information: This is an open-access article distributed under the terms of the Creative Commons Attribution License, which permits unrestricted use, distribution, and reproduction in any medium, provided the original work is properly cited. 